\title{
PREPARATION AND APPLICATION OF GLUTARALDEHYDE CROSS-LINKED CHITOSAN COATED BENTONITE CLAY CAPSULES: CHROMIUM(VI) REMOVAL FROM AQUEOUS SOLUTION
}

\author{
TÜRKAN ALTUN * \\ Department of Chemical Engineering, Konya Technical University, Konya 42150, Republic of Turkey.
}

\begin{abstract}
New sources in literature have explained that more efficient biosorbents can be developed from natural adsorbents. One of the methods to make these natural adsorbents more efficient is preparation of composites. Hydroxyl $(-\mathrm{OH})$ and amino $\left(-\mathrm{NH}_{2}\right)$ groups within the structure of chitosan leads adsorbents to have a binding potential with heavy metals. In this study, a composite adsorbent made of chitosan and bentonite clay was prepared. Bentonite clay and chitosan-coated Bentonite clay composite capsules (BC) were characterized in terms of FTIR and SEM analysis. (BC) composite adsorbent was used for the adsorption of Cr(VI) ions from aqueous solution. The effects of some parameters such as $\mathrm{pH}$, adsorbent dosage, adsorbate concentration, temperature and contact time on the adsorption of $\mathrm{Cr}(\mathrm{VI})$ on BC were investigated with batch studies. In order to evaluate the experimental data, Langmuir, Freundlich, Scatchard and Dubinin-Radushkevich (D-R) adsorption isotherm models were used for the analysis of adsorption equilibrium. The adsorption process was well fitted to Scatchard adsorption isotherm. While bentonite clay had $11,076 \mathrm{mg} / \mathrm{g}$ maximum adsorption capacity, $\mathrm{BC}$ composite had $106.444 \mathrm{mg} / \mathrm{g}$ maximum adsorption capacity for the removal of $\mathrm{Cr}(\mathrm{VI})$ ions $\left(25^{\circ} \mathrm{C}, \mathrm{pH} 2\right.$, contact time 60 minutes). It was concluded that chitosan-bentonite composite adsorbent can be effectively used for the removal of $\mathrm{Cr}(\mathrm{VI})$.
\end{abstract}

Keywords: Composite, Chitosan, Bentonite clay, $\mathrm{Cr}(\mathrm{VI})$, Adsorption, Isotherm.

\section{INTRODUCTION}

Various pollutants such as organic compounds, heavy metals and oxyanions emerge as a result of industrial applications. Especially organic pollution combining with heavy metals should be taken into consideration as an important problem in terms of environment. Since these pollutants and their derivatives are carcinogenic and have toxic effect on humans, animals as well as aquatic plants and animals, they should be removed via wastewater treatment methods. Among these methods, adsorption is known as the most economic and effective treatment method $[1,2]$. In order to obtain an efficient adsorption process, selection of an appropriate adsorbent is very important. Depending on the surface properties, most of the adsorbents can just remove either organic pollutants or heavy metals [3]. For this reason, instead of using different adsorbents, alternative adsorbent materials are required to remove both organic pollutants and heavy metals at the same time.

Since time immemorial, the clays have been an important part of human life. The clays attract attention with their wide area of usage from decorative belongings to adsorption, cement production, filtration and nanocomposite production with developing technology. The clays are preferred as an adsorbent for the removal of many pollutants since they are cheap and they have good properties even at very low amounts. Montmorillonite clay, as a well-known important one, has a very high surface area. It might adsorb pollutants in higher amounts when compared to other clay minerals $[1,4,5]$.

The main component of bentonite is montmorillonite clay which determines its properties. Bentonite is frequently formed by variation of volcanic ash. It is mainly consisting of smectite minerals. The general form of smectite minerals is montmorillonite clay. Bentonite has a chemical structure consisting of silisium and aluminum (silicon and aluminum) $\left(\mathrm{Al}_{2} \mathrm{O}_{3} \cdot 4 \mathrm{SiO}_{2} \cdot \mathrm{H}_{2} \mathrm{O}\right)$. Bentonite has a wide range of usage fields such as a binding agent for mould preparation in iron casting, as a waste adsorber in cat litter, as a binding agent for iron ore pellet production, as pollutant remover in oil production, as animal feed supplement, as filling material in pharmaceutical and cosmetic industry, as adsorbent, in detergent and liquid soap production, paper manufacturing as well as dye and lustering process [6].

Due to toxic and carcinogenic effects of heavy metals on humans and living things in aquatic environment, heavy metal pollution has attracted attention [7]. Recently, accelerating industrialization has resulted in increase and accumulation of $\mathrm{Cr}(\mathrm{VI})$ ions which is one of the most commonly found metals in water and environment. Chromium is generally used as corrosion control agent for dye and pigment production, leather tanning process, electroplating industry, metal cutting process, explosive material manufacturing, mining and ore processing activities, metallurgical industry, etc. [7]. In the wastes of these industrial processes, generally toxic amount of $\mathrm{Cr}(\mathrm{VI})$ mixes with sewage.
Depending on the $\mathrm{pH}$ of waste solution, $\mathrm{Cr}(\mathrm{VI})$ can be found in the forms of $\left(\mathrm{Cr}_{2} \mathrm{O}_{7}{ }^{-2},\left(\mathrm{HCr}_{2} \mathrm{O}_{7}\right)^{-},\left(\mathrm{HCrO}_{4}\right)^{-}\right.$and $\left(\mathrm{CrO}_{4}\right)^{-2}$. This creates serious threats for both human and environmental health [8].

The main treatment methods for the removal of $\mathrm{Cr}(\mathrm{VI})$ ions are chemical precipitation, reverse osmosis, ion exchange and adsorption. Chemical precipitation method has some disadvantages like production of toxic chemical treatment sludge, requiring chemicals continuously and having a very high operating cost. Moreover, reverse osmosis and ion exchange with commercial resins have limited usage since they have also high investment and operating costs as well as they need qualified staff in reverse osmosis for the control of process. However, removal of heavy metals from aqueous solutions by using adsorption method with low-cost adsorbents might be both economic and effective [9]. For the removal of $\mathrm{Cr}(\mathrm{VI})$, very little costly organic waste materials such as agricultural and industrial wastes [10-12], natural clays [4, 13, 14] and activated carbon [15] and the composites of these natural adsorbents can be used. In recent years, the researchers have tried various composite production methods in order to activate the adsorbents. It was observed that formation of different composites from natural adsorbents activated them and their adsorption capacities increased [16-18].

Heavy metal adsorption process with clays is a significant treatment technology that does not lose its importance. However, adsorption with natural clays might take longer time. Formation of clays with biosorbents such as chitosan increased the alternatives for new adsorbents. For this aim, clay composites are synthesized by different methods. Both clay and chitosan can be found easily in nature. For clay-chitosan composites, the disadvantages mentioned previously disappear and they can be used for heavy metal removal from aqueous solutions successfully with a certain performance. In addition to this, there are studies related with heavy metal removal from wastewater by these adsorbents [19-22]. Hydroxyl (-OH) and amino $\left(-\mathrm{NH}_{2}\right)$ groups in the structure of chitosan have a potential to make bonds with heavy metals [23]. Therefore, the adsorption performance of $\mathrm{BC}$ prepared as a composite was investigated for the removal of $\mathrm{Cr}(\mathrm{VI})$ ions from aqueous solution.

In the literature, there are available adorbents prepared with different methods and different bentonite clays and applications of these adsorbents. In the literature, related to bentonite; $\mathrm{Cr}(\mathrm{VI})$ adsorption with chitosan/bentonite composite [19], preparation and characterization of bentonite-chitosan nano composite [24], removal of different impurities (dyes, phenolic compounds, fluoride, metals and ions) from aqueous solutions with various chitosanbentonite nanocomposites [25], comparative and competitive adsorption of copper, lead and nickel with powder adsorbent chitosan immobilized on bentonite [26], use of chitosan impregnated modified bentonite as an adsorbent for remediation of oil spill from aqueous solution [27], $\mathrm{Mn}^{2+}$ modified bentonite 
for the removal of fluoride from aqueous solution [1], performance of $5 \%$ bentonite/chitosan nanocomposite in the removal of $\mathrm{Cr}$ (VI) ions from wastewater [18], removal of $\mathrm{Pb}$ (II) by magnetic bentonite prepared from $\mathrm{Fe}_{3} \mathrm{O}_{4}$ and bentonite [28], bilateral adsorption of silver and copper onto bentonite, adsorption of indium (III) ions from aqueous solution using chitosan coated bentonite beads [29] studies are available.

Although there are studies about bentonite in the literature, there is no study in the literature about the removal of $\mathrm{Cr}$ (VI) from aqueous solutions by chitosan coated bentonite clay capsules (BC) used in this study. In this present study, composite capsules were prepared from commercial bentonite and chitosan. They were investigated in terms of their efficiency for the adsorption of toxic $\mathrm{Cr}(\mathrm{VI})$ after preparing them as a composite adsorbent. In this regard, the effects of metal concentration, adsorbent dosage, $\mathrm{pH}$, temperature and contact time were investigated for the removal of $\mathrm{Cr}(\mathrm{VI})$ by using $\mathrm{BC}$. For the evaluation of experimental data, Langmuir, Freundlich, Scatchard and Dubinin-Radushkevich (D-R) adsorption isotherm models were investigated and used for the adsorption equilibrium analysis of bentonite clay and $\mathrm{BC}$ for $\mathrm{Cr}(\mathrm{VI})$. The adsorption capacity of $\mathrm{Cr}$ (VI) with BC (from Scatchard isotherm) was calculated quite high.

\section{EXPERIMENTAL}

\subsection{Materials}

Bentonite $\left(\mathrm{Al}_{2} \mathrm{O}_{3} 4 \mathrm{SiO}_{2} \cdot \mathrm{H}_{2} \mathrm{O}, 180.1 \mathrm{~g} / \mathrm{mol}\right.$ ), chitosan (medium molecular weight), $\mathrm{K}_{2} \mathrm{Cr}_{2} \mathrm{O}_{7}$ and $\mathrm{NaOH}$ were purchased from Sigma-Aldrich. Glutaraldehyde solution (GA) (25\% in water, v:v), acetic acid and $\mathrm{HCl}$ were obtained from Merck. Methanol, on the other hand, was supplied from AnalaR Normapur. All the chemicals used in the experiments were of analytical grade and distilled water was used to prepare the required solutions.

\subsection{Apparatus}

In the adsorption experiments, GFL 3033 model shaker was used to mix the solutions. The Orion 900S2 model $\mathrm{pH}$ meter with internal reference electrodes and glass electrodes was used for $\mathrm{pH}$ measurements of solutions. The UVVisible Spectrophotometer (Shimadzu UV-1700) was used for the determination of $\mathrm{Cr}(\mathrm{VI})$ in solutions. FTIR spectrum analysis was performed with Bruker VERTEX 70 FT-IR spectrometer. Microstructure of the Bentonite and BC was examined using of scanning electron microscope (SEM, ZEISS evo LS10).

\subsection{Preparation of bentonite-chitosan composites}

In $50 \mathrm{~mL}$ of $2 \%$ acetic acid, $1 \mathrm{~g}$ of chitosan was dissolved. $0.5 \mathrm{~g}$ of bentonite was added to the chitosan solution. The mixture was stirred for two hours to get a homogeneous mixture and then, the mixture was placed in a burette. This mixture was dropped into a coagulation solution $(100 \mathrm{ml}$ deionized water, $30 \mathrm{~g}$ $\mathrm{NaOH}, 150 \mathrm{ml}$ methanol) [23]. chitosan-coated Bentonite clay composite capsules were kept in this solution overnight. After that, the composite capsules were removed from its solution via filtering. Until neutralization, the composite capsules were washed with deionized water. Then, the composite capsules were transferred to cross linking solution including $0.3 \mathrm{ml} \mathrm{GA}$ and $30 \mathrm{ml}$ methanol. This mixture was refluxed 6 hours at $70^{\circ} \mathrm{C}$. At the end, these composite capsules were washed with more ethanol and deionized water in order to remove excess and unreacted glutaraldehyde molecules. Finally, they were dried at room temperature. These composite capsules were analyzed for characterization and then used for $\mathrm{Cr}(\mathrm{VI})$ removal to understand their performance in adsorption process under different experimental conditions.

\subsection{Characterization of Bentonite-chitosan composite}

\section{FTIR (Fourier Transform Infrared) spectroscopy}

FTIR spectra of raw bentonite, chitosan-coated bentonite clay composite capsules and $\mathrm{Cr}(\mathrm{VI})$-loaded composite capsules were taken in range of 4000-400 $\mathrm{cm}^{-1}$ with Bruker Vertex FTIR Spectrum Photometer (4 $\mathrm{cm}$ resolution).

\section{Scanning Electron Microscope/Energy Dispersive X-Ray (SEM/EDX)}

Surface characterization of raw bentonite, chitosan-coated Bentonite clay composite capsules and $\mathrm{Cr}(\mathrm{VI})$-loaded composite capsules was determined by ZEISS evo LS10 scanning electron microscope.

\subsection{Batch $\mathrm{Cr}(\mathrm{VI})$ adsorption experiments}

The stock solution of $\mathrm{Cr}(\mathrm{VI})$ was prepared by dissolving $\mathrm{K}_{2} \mathrm{Cr}_{2} \mathrm{O}_{7}$ in deionized water. The solution concentrations required for the adsorption study were prepared by diluting this stock solution of $\mathrm{Cr}(\mathrm{VI})$. The $\mathrm{pH}$ of the prepared solutions was adjusted to the wanted values by using $0.1 \mathrm{~mol} / \mathrm{L} \mathrm{NaOH}$ and 0.1 $\mathrm{mol} / \mathrm{L} \mathrm{HCl}$ solutions. $\mathrm{pH}$ measurements were carried out via Orion $900 \mathrm{~S} 2 \mathrm{pH}$ meter. Chitosan-coated Bentonite clay composite capsules $(0.04 \mathrm{~g})$ were added to $\mathrm{Cr}(\mathrm{VI})$ solution (58 ppm-10 ml Cr(VI), $\mathrm{pH}$ 2). Adsorbent-adsorbate interaction was performed with a mechanic stirrer at $200 \mathrm{rpm}$ for 1 hours. After adsorption process, the amount of $\mathrm{Cr}(\mathrm{VI})$ remaining in the solution filtered with Whatman filter paper was determined with UV-Visible spectrophotometer (Shimadzu UV1700).at $540 \mathrm{~nm}$ using the 1,5 diphenyl carbazide reagent [30,31]. The amount of $\mathrm{Cr}(\mathrm{VI})$ removed by per $\mathrm{g}$ adsorbent was calculated using the following equation. $\left(q_{e}\right)$ :

$$
q_{e}=\left(C_{i}-C_{e}\right) V / W
$$

where $q_{e}$ is the metal-sorption capacity of the adsorbent (mg.g $\left.{ }^{-1}\right) ; C_{e}$ and $C_{i}$ are equilibrium concentrations and the initial of $\mathrm{Cr}(\mathrm{VI})$ ion, respectively; and $W$ is the amount of adsorbent (g) $V$ is the volume of solution (L) [32]. The effects of adsorbent dosage (0.01-0.1 g), contact time (0-240 minutes), initial $\mathrm{Cr}(\mathrm{VI})$ concentration (10-260 ppm), $\mathrm{pH}$ of $\mathrm{Cr}(\mathrm{VI})$ solution (2-7) and temperature (25, 35,45 and $55^{\circ} \mathrm{C}$ ) on the adsorption of $\mathrm{Cr}(\mathrm{VI})$ with the $\mathrm{BC}$ were investigated. These parameters were examined and the optimum conditions were found for $\mathrm{Cr}(\mathrm{VI})$ adsorption with BC. \% adsorption at equilibrium was calculated by an equilibrium written as follows:

$$
\operatorname{Adsorption}(\%)=\left[\left(C_{i}-C_{e}\right) / C_{i}\right] \times 100
$$

\section{RESULTS AND DISCUSSION}

3.1. Characterization of bentonite, chitosan-coated Bentonite clay composite capsules $(\mathrm{BC})$ and $\mathrm{BC}-\mathrm{Cr}(\mathrm{VI})$

\section{FTIR analysis (Fourier Transform Infrared) spectroscopy}

For the characterization of the adsorbents, FTIR spectra of bentonite clay, chitosan-coated Bentonite clay composite capsules (BC) and $\mathrm{BC}-\mathrm{Cr}(\mathrm{VI})$ were taken in the range of 4000-500 $\mathrm{cm}^{-1}$ wavenumber and are sowed in Figure 1. When the spectra were investigated, it was observed that characteristic vibration bands were found for bentonite at $3637 \mathrm{~cm}^{-1}$ (-OH stretching), $1635 \mathrm{~cm}^{-1}$ (H-O$\mathrm{H}$ bending), 1116 and $1000 \mathrm{~cm}^{-1}$ ( $\mathrm{Si}-\mathrm{O}$ stretching), $918 \mathrm{~cm}^{-1}$ ( $\mathrm{Al}-\mathrm{OH}$ stretching), $796 \mathrm{~cm}^{-1}$ ((Al, Mg)-OH stretching), $648 \mathrm{~cm}^{-1}$ (Al-OH bending), $518 \mathrm{~cm}^{-1}$ (vibration bands belonging to Si-O bending) wavenumber. Vibration bands of $\mathrm{BC}$ (chitosan-coated Bentonite clay composite capsules), on the other hand, were observed at $3691 \mathrm{~cm}^{-1}$ (band because of overlapping of N-H and O-H stretching bands), $3291 \mathrm{~cm}^{-1}$ (a wide $\mathrm{O}-\mathrm{H}$ band), $2870 \mathrm{~cm}^{-1}$ (aliphatic C-H stretching), $2360 \mathrm{~cm}^{-1}$ (C=C stretching), $1585 \mathrm{~cm}^{-1}$ (N-H bending), 1420 and $1315 \mathrm{~cm}^{-1}$ (C-N stretching), $1018 \mathrm{~cm}^{-1}$ (vibration bands of C-O stretching) wavelengths), $916 \mathrm{~cm}$ ${ }^{1}$ (Al-OH stretching), $798 \mathrm{~cm}^{-1}$ ((Al, Mg)-OH stretching), $520 \mathrm{~cm}^{-1}$ (vibration bands belonging to $\mathrm{Si}-\mathrm{O}$ bending). The spectrum of $\mathrm{BC}$ composite indicated the combination of characteristic groups found in chitosan and bentonite [19]. After $\mathrm{Cr}(\mathrm{VI})$ adsorption of $\mathrm{BC}$ composite $(\mathrm{BC}-\mathrm{Cr}(\mathrm{VI}))$, it was observed that the intensity of some bands decreased and some bands shifted. The N-H, O-H stretching band was seen at $3691 \mathrm{~cm}^{-1}$ for BC shifted to $3627 \mathrm{~cm}^{-1}$ and and its intensity decreased; a wide $\mathrm{O}-\mathrm{H}$ band at $3265 \mathrm{~cm}^{-1}$ of intensity decreased, the bands belonging to $\mathrm{C}-\mathrm{H}$ vibration between $2858 \mathrm{~cm}^{-1}$ shifted to $2870 \mathrm{~cm}^{-1}$ as well as its intensity decreased; $\mathrm{N}-\mathrm{H}$ bending vibration band at $1585 \mathrm{~cm}^{-1}$ shifted to $1647 \mathrm{~cm}^{-1}$ and its intensity decreased. The band of C-N bending bands at 1420 and $1315 \mathrm{~cm}^{-1}$ shifted to $1396 \mathrm{~cm}^{-1}$ and its intensity increased; C-O stretching band at $1018 \mathrm{~cm}^{-1}$ shifted to $1014 \mathrm{~cm}^{-1}$ its intensity decreased; the Al-OH stretching band at $916 \mathrm{~cm}^{-1}$ shifted to $871 \mathrm{~cm}^{-1}$; the intensity of the ( $\left.\mathrm{Al}, \mathrm{Mg}\right)-\mathrm{OH}$ stretching band at $798 \mathrm{~cm}^{-1}$ decreased; and the vibration band belonging to $\mathrm{Si}-\mathrm{O}$ bending band at $520 \mathrm{~cm}^{-1}$ shifted to $518 \mathrm{~cm}^{-1}[18,24]$. Figure 1 indicated that $\mathrm{BC}$ composite capsules had many functional groups ( $\mathrm{Si}-\mathrm{OH}, \mathrm{Al}-\mathrm{OH}, \mathrm{N}-\mathrm{H}, \mathrm{C}-\mathrm{O}, \mathrm{O}-$ $\mathrm{H}$, etc.). These functional groups are important for the adsorption of $\mathrm{Cr}(\mathrm{VI})$. As stated in prior studies in literature, the transfer of chitosan onto the bentonite and penetration of chitosan to the clay matrix were supplied via the physical and chemical interactions between bentonite and chitosan. FTIR results indicated that 
BC might be an effective adsorbent for the adsorption of $\mathrm{Cr}(\mathrm{VI})$. Bands of $\mathrm{BC}$; it consists of a mixture of bands on chitosan and bentonite. [18, 19, 26, 33].

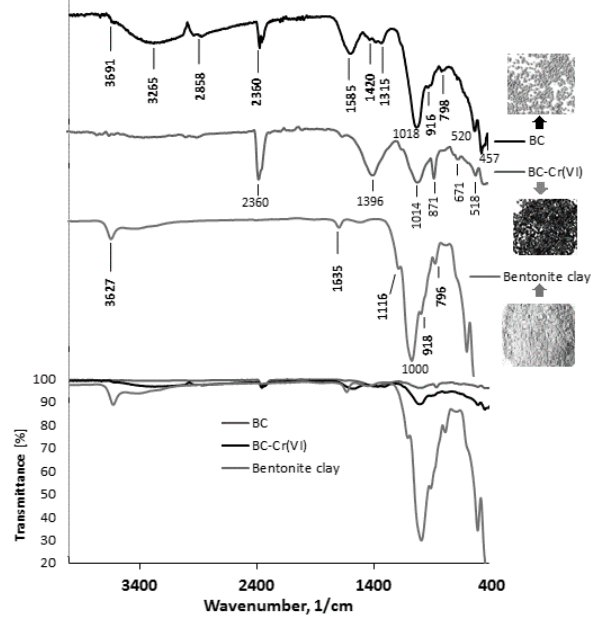

Figure 1. FTIR spectrum of Bentonite clay (blue), chitosan-coated Bentonite clay composite capsules (BC-red) and chitosan-coated Bentonite clay composite capsules-Cr(VI) (BC-Cr(VI)-black).

\section{Surface morphology}

Microstructure of the Bentonite and BC was examined using of scanning electron microscope (SEM, ZEISS evo LS10). Samples were covered with gold to perform SEM analysis. The SEM of bentonite (a), BC (b) and BC-Cr(VI) are shown Figure 2. According to the results of SEM analysis, it was indicated that chitosan-coated Bentonite clay composite capsules were successfully synthesized and the pollution caused by $\mathrm{Cr}(\mathrm{VI})$ ions was removed by using these composite capsules. After chitosan-coated Bentonite clay composite capsules were formed, the changes in the shape of bentonite particles can be seen at Figure 2. It was also determined that the composite capsules were sphere in shape and the average particle size of them was lower than 100 micrometer. The surface change in the SEM micrographs demonstrated the structure of the adsorbent after and before $\mathrm{Cr}(\mathrm{VI})$ adsorption. The structure of $\mathrm{BC}$-composite capsules is observed as rough and folded. After the adsorption of $\mathrm{Cr}(\mathrm{VI})$, the surfaces of the BC capsules had a very smooth surface. This smooth structure showed that the surface filled and that $\mathrm{Cr}(\mathrm{VI})$ ions were adsorbed on the $\mathrm{BC}$ surface.

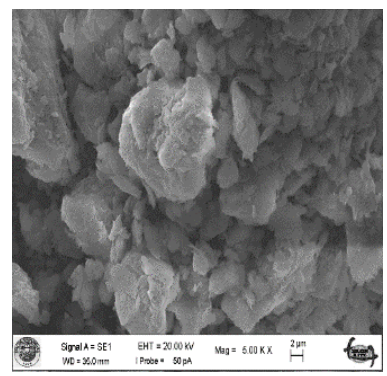

(a) Bentonite

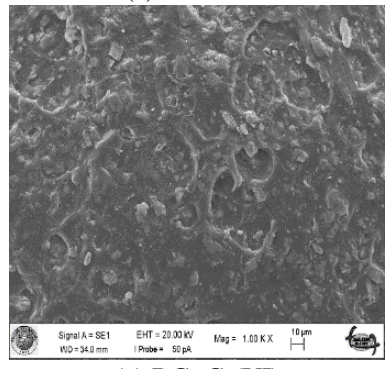

(c) BC- Cr(VI)

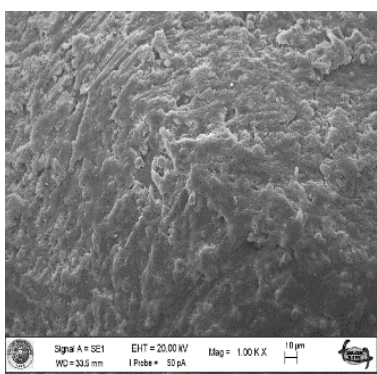

(b) $\mathrm{BC}$

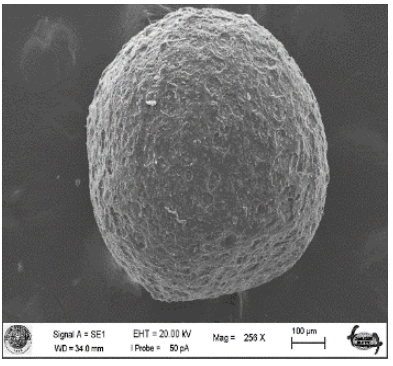

(d) BC-Cr(VI)
Figure 2. SEM micrograph of Bentonite clay (a), chitosan-coated Bentonite clay composite capsules (BC-b) and chitosan-coated Bentonite clay composite capsules-Cr(VI) (BC-Cr(VI)-c, d).
3.2. Adsorption performances of $\mathrm{Cr}(\mathrm{VI})$ ion with chitosan-coated Bentonite clay composite capsules (BC)

\subsubsection{Effect of $\mathrm{pH}$}

$\mathrm{pH}$ is one of the important parameters in the adsorption because it affects the surface mechanism of the adsorbent, in other words, to the binding points of pollutant and the adsorbent. $\mathrm{pH}$ value of the solution affects the surface charge of the adsorbent, the degree of ionization and the adsorbed species.

Moreover, adsorption degree also changes depending on the $\mathrm{pH}$ value since the concentration of dissolved species will change because of precipitation and hydrolysis of metal ions. Since there is a competition between metal ions and hydrogen ions for active areas on the surface of the adsorbent, the $\mathrm{pH}$ of the media greatly influences metal binding. Therefore, the effect of $\mathrm{pH}$ on the adsorption of $\mathrm{Cr}(\mathrm{VI})$ was the first study and the results was given in Figure 3a.

As it can be seen in Figure 3a, at $\mathrm{pH} 2.1$, while $58 \mathrm{ppm} \mathrm{Cr}(\mathrm{VI})$ ion was removed with $95 \%$, this rate decreased to $28 \%$ at $\mathrm{pH}=5$. There is an inverse proportion between $\mathrm{Cr}(\mathrm{VI})$ removal and $\mathrm{pH}$ values. As the $\mathrm{pH}$ decreased, the amount of $\mathrm{Cr}(\mathrm{VI})$ adsorbed by BC was observed to be increased. This situation can be attributed the cationic structure of the adsorbent and to the presence of excess $\mathrm{OH}^{-}$ions in the solution. Since the initial $\mathrm{pH}$ value of the solution both affects metal binding sites and water chemistry, it is necessary to determine optimum $\mathrm{pH}$ correctly to evaluate the efficiency of adsorption process [11]. The optimum $\mathrm{pH}$ of the $\mathrm{Cr}(\mathrm{VI})$ adsorption with the $\mathrm{BC}$ composite adsorbent was found to be approximately 2 .

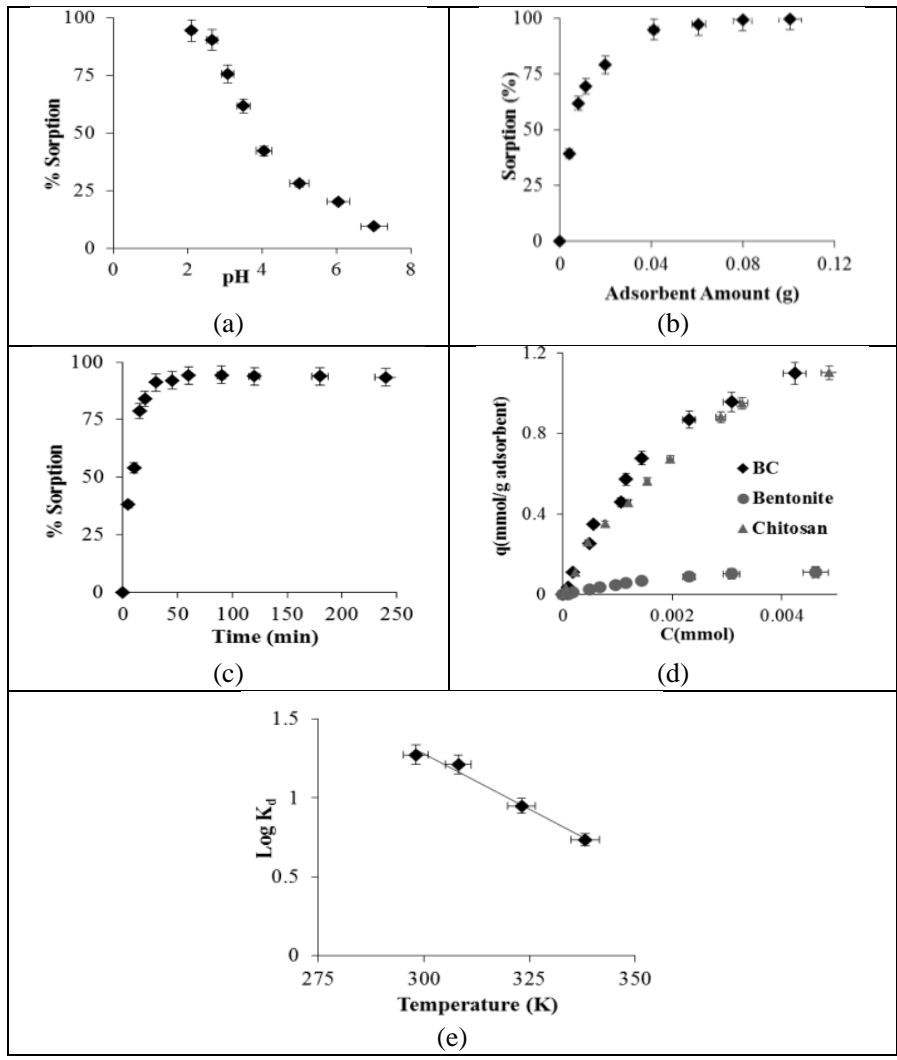

Figure. 3. (a) Effect of $\mathrm{pH}$ on the removal of $\mathrm{Cr}(\mathrm{VI})$ using $\mathrm{BC}$ (adsorbent amount: $4 \mathrm{~g} / \mathrm{L}$, initial concentration of $\mathrm{Cr}(\mathrm{VI}): 58 \mathrm{ppm}$, temperature: $25 \pm 1{ }^{\circ} \mathrm{C}$, and contact time: $60 \mathrm{~min}$ for BC). (b) Effect of adsorbent dosage on removal of $\mathrm{Cr}(\mathrm{VI})$ using $\mathrm{BC}$ (initial concentration of $\mathrm{Cr}(\mathrm{VI}): 58 \mathrm{ppm}$, initial solution $\mathrm{pH}: 2$, contact time: $60 \mathrm{~min}$, and temperature: $25 \pm 1{ }^{\circ} \mathrm{C}$ for BC). (c) Effect of contact time on removal of $\mathrm{Cr}(\mathrm{VI})$ with $\mathrm{BC}$ (initial concentration of $\mathrm{Cr}(\mathrm{VI}): 58 \mathrm{ppm}$, initial solution $\mathrm{pH}$ : 2 , adsorbent amount $4 \mathrm{~g} / \mathrm{L}$, and temperature $25 \pm 1{ }^{\circ} \mathrm{C}$ for $\mathrm{BC}$ ). (d) Adsorption isotherms of Bentonite clay, Chitosan and $\mathrm{BC}$ (solution $\mathrm{pH}$ : 2, adsorbent amount: $4 \mathrm{~g} / \mathrm{L}$, contact time: $60 \mathrm{~min}$, and temperature: $25 \pm 1{ }^{\circ} \mathrm{C}$ for $\mathrm{BC}$ ). (e) Effect of temperature on the adsorption of $\mathrm{Cr}(\mathrm{VI})$ by $\mathrm{BC}$ (initial concentration of $\mathrm{Cr}(\mathrm{VI}): 58 \mathrm{ppm}$, adsorbent amount: $4 \mathrm{~g} / \mathrm{L}$, contact time: $60 \mathrm{~min}$, and solution $\mathrm{pH}: 2$ for $\mathrm{BC}$ ). 


\subsubsection{Adsorbent Dosage}

In terms of both the efficiency and cost of the process, it is of great importance to determine the appropriate adsorbent dosage in the adsorption processes. Moreover, the amounts of functional groups present on the surface binding points of the adsorbent have an important role for the removal of target metals. In this part of the study, a series of experiments were performed with $58 \mathrm{ppm} \mathrm{Cr}(\mathrm{VI})$ solution in varying adsorbent dosages $(0.01-0.1 \mathrm{~g})$ and as a result, the effect of adsorbent amount on $\mathrm{Cr}(\mathrm{VI})$ adsorption was investigated.

When the graph given in Fig. 3b was investigated, it was observed that as the adsorbent dosage increased, the sorption rate of metal removal also increased. While $\mathrm{Cr}(\mathrm{VI})$ removal was $69 \%$ with $0.01 \mathrm{~g}$ adsorbent, it increased to $94.95 \%$ as the adsorbent dosage was increased to $0.04 \mathrm{~g}$. When the amount of adsorbent was $0.1 \mathrm{~g}$, the \% sorption value was $99.84 \%$. After plateau value, the increase in the amount of BC does not significantly affect the $\mathrm{Cr}(\mathrm{VI})$ adsorption. Since the increase in sorption decreased after $0.04 \mathrm{~g}$ adsorbent amount, the optimum amount of adsorbent was taken as $0.04 \mathrm{~g}$. After this point; since the adsorption event was an equilibrium event, the effect of increasing the amount of $\mathrm{BC}$ upon removal of $\mathrm{Cr}(\mathrm{VI})$ was not high. At the beginning, the increased adsorption percentage of $\mathrm{Cr}(\mathrm{VI})$ ions could be attributed to the increased availability of adsorption sites along with an increase in the amount of BC. In balance, the percentage of $\mathrm{Cr}(\mathrm{VI})$ adsorption probably remained constant due to saturation of surface areas in the adsorbent. Since the surface area increased as increasing the adsorbent dosage, the amount of adsorbed $\mathrm{Cr}(\mathrm{VI})$ per unit mass of adsorbent also increased. Since adsorption is a surface phenomenon, the efficiency and intensity of adsorption process is directly proportional to surface area. Similar results were obtained in the literature $[2,35,36]$.

\subsubsection{Effect of Contact Time On Cr(VI) Removal}

In order to mention the efficiency of the process, contact time is another important parameter that should be investigated in adsorption. In this study, metal removal percentages were calculated in terms of contact time while all other parameters were kept constant. $0.04 \mathrm{~g}$ adsorbent was mixed with $58 \mathrm{ppm}$ $\mathrm{Cr}(\mathrm{VI})$ solution at $\mathrm{pH} 2$ at varying time intervals and sorption percentage was drawn against contact time (Figure $3 \mathrm{c}$ ). When the graph was investigated, adsorbed metal amount rapid increased within a contact time of 0- 60 minutes, however, a significant difference was not observed for the measurements after 60 minutes. As it can be seen in Figure 3c, because of $\mathrm{Cr}(\mathrm{VI})$ ions adsorbed on the outer surface of the adsorbent, initial adsorption rate was higher. At initial stage, since adsorbent had a wide surface area for the adsorption of metal ions and adsorbent centers were free, metals ions easily interact with these centers and therefore the adsorption was faster. As the adsorption centers on the surface were occupied, metal ions were transferred from outer surface of the adsorbent to the inner surface, metal removal rate was got under control and adsorption process reached an equilibrium. Slow adsorption after initial period might be due to slower diffusion of solution through the adsorbent $[37,38]$.

\subsubsection{Effect of Initial Cr(VI) Concentration On the Adsorption Process}

In this part of the study carried out with different initial concentrations, the relationship between equilibrium concentrations obtained and amount of adsorbed metal ion per unit mass of adsorbent was investigated and isotherm data were calculated by drawing adsorption isotherms. The effect initial $\mathrm{Cr}(\mathrm{VI})$ concentration on removal of $\mathrm{Cr}(\mathrm{VI})\left(10-260 \mathrm{mg} / \mathrm{L}\right.$ concentration range, $25 \pm 1{ }^{\circ} \mathrm{C}$, initial solution $\mathrm{pH} 2$, adsorbent amount $25 \mathrm{~g} / \mathrm{L} ; 4 \mathrm{~g} / \mathrm{L}$ for bentonite clay and $\mathrm{BC}$ respectively) with bentonite and $\mathrm{BC}$ is shown in Figure $3 \mathrm{~d}$. For the determination of suitability of these data to the isotherm models, it is necessary to present the relationship between equilibrium concentration $\left(\mathrm{C}_{\mathrm{e}}\right)$ and $\mathrm{C}_{\mathrm{e}} / \mathrm{q}_{\mathrm{e}}$. This was explained with the equations given in Table 1, then the isotherm constants were calculated with the slopes of the curves and the y-intercept of the equations. In these equations, $\mathrm{C}_{\mathrm{e}}$ indicated metal concentration at equilibrium $(\mathrm{mg} / \mathrm{L}) ; \frac{x}{m}=q_{e}$ was the amount of adsorbed metal ion by the adsorbent $(\mathrm{mg} / \mathrm{g})[28,39-41]$.

In Table 1, the constants of Langmuir, Freundlich Scatchard and DubininRadushkevich (D-R) isotherms are given. Table 1 shows the results of the modified Langmuir, Freundlich, Scatchard and D-R isotherms analysis for the adsorption of $\mathrm{Cr}(\mathrm{VI})$ on the bentonite clay, chitosan and $\mathrm{BC}$ from aqueous solutions. The equilibrium relationships between the adsorbent and $\mathrm{Cr}(\mathrm{VI})$ are explained by adsorption isotherms. Correlation coefficients $\left(\mathrm{R}^{2}\right.$ value $)$ calculated from modified Langmuir, Freundlich, Scatchard, and D-R isotherms models. When all isotherms were compared, $\mathrm{R}^{2}$ values were close to each other. (Figure $4 \mathrm{a}, \mathrm{b}$ ). Therefore, it is thought to have more than one adsorption mechanism. The parameters of the isotherms showed respectively for bentonite clay, chitosan and BC in Figure 4a, b are given in Table 1. For Freundlich isotherm, $\mathrm{k}$ and $\mathrm{n}$ are constant values. For Langmuir isotherm, $\mathrm{A}_{\mathrm{s}}$ is the adsorption capacity ( $\mathrm{mg} / \mathrm{g}$ adsorbent), $\mathrm{K}_{\mathrm{b}}$ is a constant related with adsorption energy $[28,32,35]$. In Scatchard isotherm, $Q_{s}$ is the adsorption capacity $(\mathrm{mg} / \mathrm{g}$ adsorbent), $\mathrm{K}_{\mathrm{s}}$ is the binding constant [2]. In Dubinin Radushkevich (D-R) isotherm, $\mathrm{E}$ indicates adsorption energy $\left(\mathrm{kJ} \mathrm{mol}^{-1}\right)$ and $\mathrm{K}$ refers to adsorption energy constant [32, 42, 43].

It is possible with D-R isotherm to calculate adsorption energy $\left(\mathrm{E}_{\mathrm{ad}} ; \mathrm{kJ} / \mathrm{mol}\right)$ which gives information about physical and chemical characteristics of adsorption. If adsorption energy is $\mathrm{E}_{\mathrm{ad}}<8 \mathrm{kj} / \mathrm{mol}$, adsorption process is physical adsorption; if $E_{a d}$ is between $8-16 \mathrm{kj} / \mathrm{mol}$, ion exchange or complex formation and if $E_{a d}>16$, then particle diffusion are dominant. For $\mathrm{Cr}(\mathrm{VI})$ adsorption with chitosan and $\mathrm{BC}, \mathrm{E}_{\mathrm{ad}}$ were found as 8.84 and $8.006 \mathrm{kj} / \mathrm{mol}$ respectively which indicated that ion exchange and complex formation were dominating the adsorption process. $\mathrm{E}_{\mathrm{ad}}$ was calculated as $7.495 \mathrm{kj} / \mathrm{mol}$ in $\mathrm{Cr}(\mathrm{VI})$ adsorption with bentonite clay. Physical adsorption is dominant in $\mathrm{Cr}(\mathrm{VI})$ adsorption process with bentonite clay. It was resulted that Scatchard isotherm was more suitable for this removal process by $\mathrm{BC}$ adsorbent with the calculated correlation coefficients. Scatchard isotherm assumes that adsorption potential was constant and the surface of the particle was homogeneous. According to this isotherm, maximum adsorption capacity of $\mathrm{BC}$ for $\mathrm{Cr}(\mathrm{VI})$ removal was calculated as $106.444 \mathrm{mg} / \mathrm{g}$ and it was determined that this capacity was higher than other adsorbents which were used in previous studies in the literature. Maximum $\mathrm{Cr}(\mathrm{VI})$ adsorption capacity of bentonite clay and chitosan was found as 11.076 and $88.705 \mathrm{mg} / \mathrm{g}$, respectively.

The maximum $\mathrm{Cr}(\mathrm{VI})$ adsorption capacity of $\mathrm{BC}$ is approximately 10 times the capacity of bentonite clay. $\mathrm{Cr}(\mathrm{VI})$ adsorption process with bentonite clay is slower and requires longer durations. The maximum adsorption capacity of the $\mathrm{Cr}(\mathrm{VI})$ ion of the bentonite clay is also low. The adsorption process with $\mathrm{BC}$ is completed shortly and the maximum adsorption capacity is obtained higher as seen in Table 1. This results showed that the interest of $\mathrm{Cr}(\mathrm{VI})$ to the $\mathrm{BC}$ composite capsule was quite high. Many investigations have been carried out related to removal of $\mathrm{Cr}(\mathrm{VI})$ from the aqueous solution with the adsorption and $\mathrm{Cr}(\mathrm{VI})$ adsorption capacities of these studies are given in Table 2. When compared with the other adsorbents in the literature, it has been found that the $\mathrm{BC}$ composite adsorbent has a considerably high capacity for the removal of $\mathrm{Cr}(\mathrm{VI})$

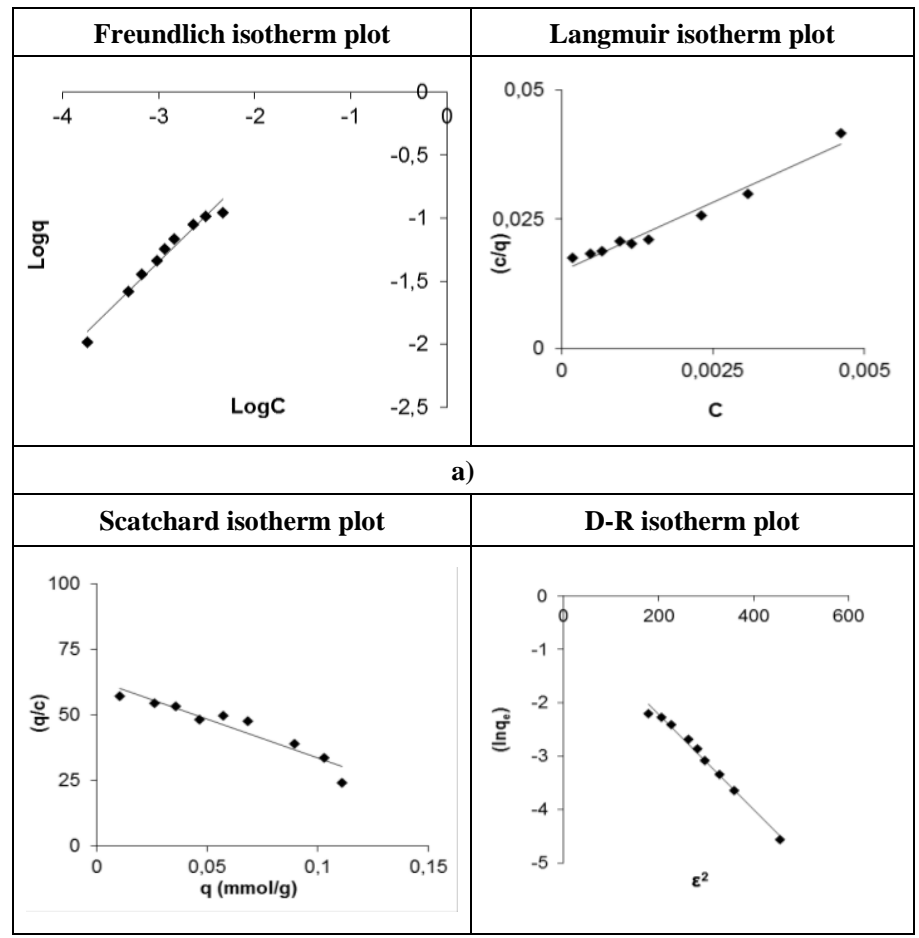



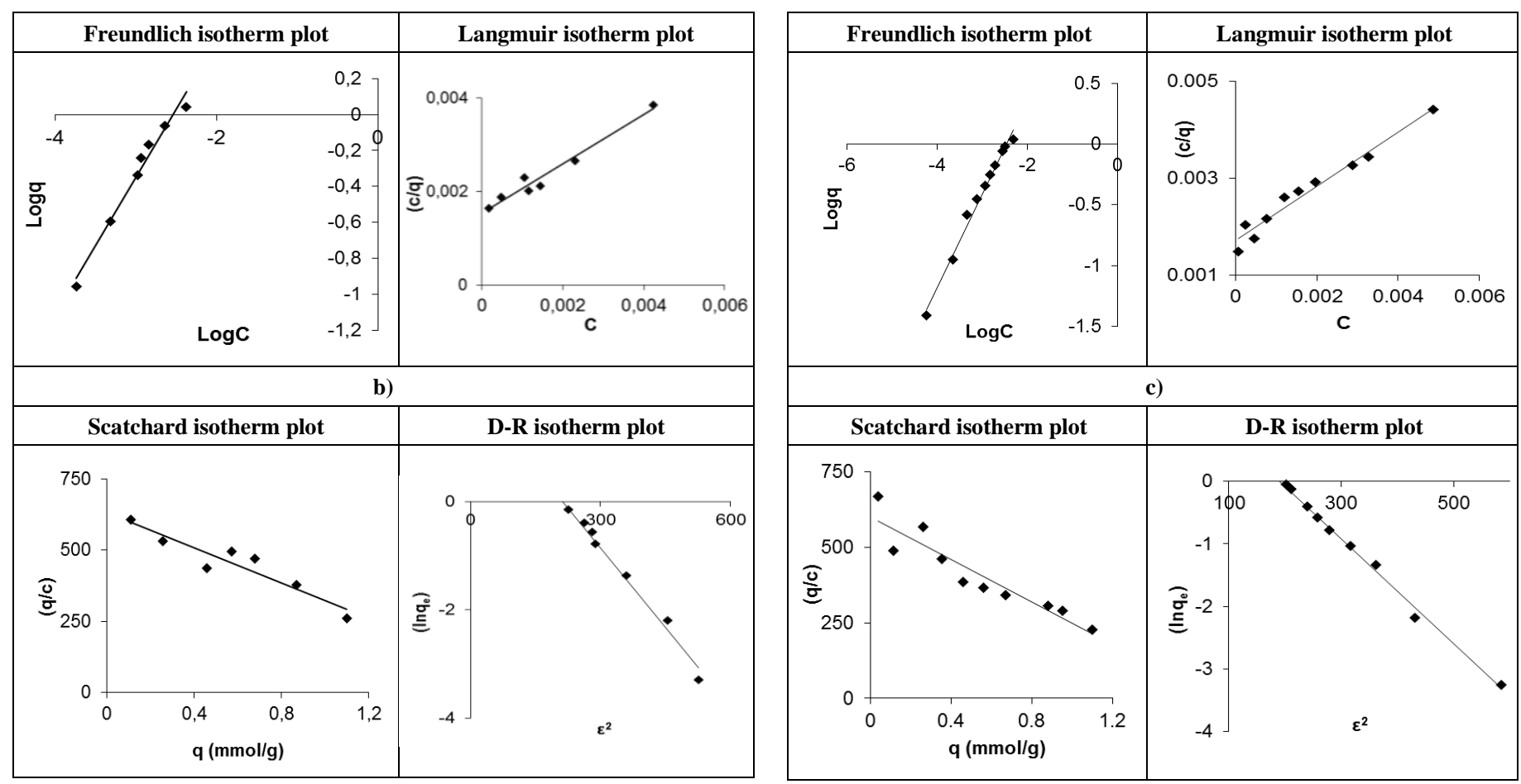

Figure 4. Langmuir, Freundlich, Dubinin-Radushkevich and Scatchard isotherms plot for the adsorption of Cr(VI) onto (a) Bentonite clay,(b) chitosan-coated Bentonite clay composite capsules (BC) and Chitosan.

Table 1. Isotherm, kinetic and thermodynamic data for removal of $\mathrm{Cr}(\mathrm{VI})$ using Bentonite clay and chitosan-coated Bentonite clay composite capsules (BC).

\begin{tabular}{|c|c|c|c|c|c|c|}
\hline Isotherm Model & Linear Equations & Curve & Parameters & Bentonite & Chitosan & BC \\
\hline \multirow{3}{*}{ Langmuir } & \multirow{3}{*}{$\frac{C_{e}}{q_{e}}=\frac{C_{e}}{A_{s}}+\frac{1}{A_{s} K_{b}}$} & \multirow{3}{*}{$\begin{array}{l}(\mathrm{Ce} / q e) \mathrm{vs} . \\
\mathrm{Ce}\end{array}$} & $\boldsymbol{A}_{s}$ & 9.770 & 93.385 & 98.620 \\
\hline & & & $K_{b}$ & 354.790 & 327.53 & 351.530 \\
\hline & & & $\mathbf{R}^{2}$ & 0.9671 & 0.963 & 0.9650 \\
\hline \multirow{3}{*}{ Freundlich } & \multirow{3}{*}{$\log q_{e}=\log K_{F}+\frac{1}{n} \log C_{e}$} & \multirow{3}{*}{$\begin{array}{l}\text { Logqe vs. } \\
\quad \log C e\end{array}$} & $k$ & 8.100 & 80.720 & 83.580 \\
\hline & & & $n$ & 1.330 & 1.294 & 1.320 \\
\hline & & & $\mathbf{R}^{2}$ & 0.968 & 0.988 & 0.976 \\
\hline \multirow{3}{*}{ Scatchard } & \multirow{3}{*}{$\left(\frac{q_{e}}{C_{e}}\right)=Q_{s} K_{s}-q_{e} K_{s}$} & \multirow{3}{*}{$q e$ vs. $q e / C e$} & $K_{s}$ & 297.160 & 351.9 & 308.820 \\
\hline & & & $Q_{s}$ & 11.076 & 88.705 & 106.444 \\
\hline & & & $\mathbf{R}^{2}$ & 0.935 & 0.8686 & 0.983 \\
\hline \multirow{3}{*}{$\begin{array}{l}\text { Dubinin } \\
\text { Radushkevich (D-R) }\end{array}$} & \multirow{3}{*}{$\begin{array}{l}\ln q_{e}=\ln X_{m}-K \varepsilon^{2} \\
\varepsilon: R T \ln \left(1+\frac{1}{C_{e}}\right) \\
\varepsilon: \text { Polanyi potential } \\
E_{a d}=\left(2 K_{1}\right)^{-\frac{1}{2}} \\
E_{a d}=\text { Adsorption Energy }\end{array}$} & \multirow{3}{*}{$\varepsilon^{2} v s . \ln q e$} & $\boldsymbol{K}$ & 0.0089 & 0.064 & 0.0078 \\
\hline & & & $\mathbf{E}_{\text {ad }}$ & 7.495 & 8.840 & 8.006 \\
\hline & & & $\mathbf{R}^{2}$ & 0.988 & 0.991 & 0.984 \\
\hline \multirow{6}{*}{$\begin{array}{l}\text { Thermodynamic } \\
\text { parameters }\end{array}$} & \multirow{6}{*}{$\Delta \mathbf{G}=\Delta \mathbf{H}-\mathbf{T} \Delta \mathbf{S}$} & & $\Delta \mathbf{H}^{\circ}(\mathrm{J} / \mathbf{m o l})$ & & 0.270 & \\
\hline & & & $\Delta \mathbf{S}^{\circ}(\mathbf{J} / \mathbf{K} \cdot \mathbf{m o l})$ & & 105.500 & \\
\hline & & \multirow{4}{*}{\multicolumn{2}{|c|}{$\Delta \mathbf{G}^{\circ}(\mathrm{J} / \mathbf{m o l})$}} & $\mathrm{T}=298 \mathrm{~K}$ & -30927.14 & \\
\hline & & & & $T=308 K$ & -32509.64 & \\
\hline & & & & $T=318 K$ & -34092.15 & \\
\hline & & & & $\mathrm{T}=328 \mathrm{~K}$ & -35674.65 & \\
\hline
\end{tabular}


Table 2. Comparative of the adsorption capacities of $\mathrm{Cr}(\mathrm{VI})$ ions onto the different adsorbents.

\begin{tabular}{|c|c|c|}
\hline Adsorbent & Adsorption capacity (mg/g) & References \\
\hline Turkish perlite with $\alpha-\mathrm{MnO}_{2}$ (PAM) & 7.60 & [2] \\
\hline Turkish perlite $\gamma-\mathrm{Fe}_{2} \mathrm{O}_{3}$ (PGI) & 8.64 & {$[2]$} \\
\hline Ti-Fe kaolinite composite & 23.47 & [4] \\
\hline Chestnut oak shells & 4.44 & [7] \\
\hline Prepared carbon with chestnut shells & 33.00 & [7] \\
\hline Smectite Natural clay & 12.50 & [13] \\
\hline Activated Smectite Natural clay with sulfuric acid & 19.23 & [13] \\
\hline Acid-treated sawdust composite beads (SDCCB) & 122.30 & [17] \\
\hline Cross-Linked Magnetic Chitosan Beads & 69.40 & [18] \\
\hline Chitosan/Zeolite film & 17.28 & [18] \\
\hline Chitosan & 35.60 & [18] \\
\hline N-2-hydroxypropyl trimethyl ammonium chloride chitosan-bentonite & 22.17 & [18] \\
\hline Cross-linked chitosan & 50.00 & [18] \\
\hline Oak wood charcoal & 30.10 & [19] \\
\hline Cross-linked chitosan/bentonite (obtained from China) composite (CCB) & 89.13 & [19] \\
\hline Oak wood charcoal ash & 46.17 & [19] \\
\hline Mesoporous NiO nanoparticles & 4.73 & [19] \\
\hline KIP 210 resin & 100.00 & [19] \\
\hline Ammonium sulfamate-bacterial cellulose & 22.30 & [19] \\
\hline Tannin-immobilized activated clay & 24.09 & [19] \\
\hline Cross-linked chitosan/bentonite composite & 89.13 & [19] \\
\hline $\begin{array}{l}\text { Chitosan(Chitosan extracted from this waste prawn shell)-modified Bijoypur clay biocomposite } \\
\text { (CHT-MC) }\end{array}$ & 73.00 & {$[21]$} \\
\hline Raw kaolinite & 11.60 & {$[22]$} \\
\hline Kaolinite activated by acid & 13.90 & {$[22]$} \\
\hline Kaolinite activated by $\mathrm{ZrO}$ & 10.90 & {$[22]$} \\
\hline Kaolinite activated by BA(Tetrabutylammonium) & 10.60 & {$[22]$} \\
\hline Bentonite-nZVI (Nanoscale zero-valent iron) nano-composite & 66.10 & {$[22]$} \\
\hline Mt-algi/PA (Alginate-montmorillonite/polyaniline) & 29.89 & {$[22]$} \\
\hline Mt(Montmorillonite)/Cellulose and Sodium & 22.20 & {$[22]$} \\
\hline Bentonite/Acid activated pillared & 1030 & {$[22]$} \\
\hline N-2-hydroxypropyl trimethyl ammonium chloride chitosan (HTCC)-bentonite nanocomposite & 22.17 & {$[25]$} \\
\hline Commercial Activated carbon (CAC). & 15.47 & [25] \\
\hline Commercial bentonite & 11.076 & In this study \\
\hline Chitosan & 88.705 & In this study \\
\hline $\mathrm{BC}$ & 106.44 & In this study \\
\hline
\end{tabular}

\subsubsection{Thermodynamic analysis}

Adsorption of $\mathrm{Cr}(\mathrm{VI})$ onto $\mathrm{BC}$ has definitely carried out different temperatures $\left(25{ }^{\circ} \mathrm{C}, 35{ }^{\circ} \mathrm{C}, 45{ }^{\circ} \mathrm{C}\right.$, and $55{ }^{\circ} \mathrm{C}$ ) for thermodynamic analysis (Figure 3e). The thermodynamic parameters including $\Delta \mathrm{H}^{\circ}, \Delta \mathrm{S}^{\circ}$ and $\Delta \mathrm{G}^{\circ}$ for the adsorption of $\mathrm{Cr}(\mathrm{VI})$ are calculated from plotted data, and the results are given in Table 1. The effect of temperature on the adsorption of $\mathrm{Cr}(\mathrm{VI})$ ions was investigated and the adsorption capacity was calculated as higher at low temperatures for BC composite capsules. By using Van't Hoff equation, a graph of $\log K_{c}$ vs. $1 / T$ was drawn, standard free energy $\left(\Delta \mathrm{G}^{\circ}\right)$, enthalpy $\left(\Delta \mathrm{H}^{\circ}\right)$ and entropy $\left(\Delta \mathrm{S}^{\circ}\right)$ changes were calculated [40].

$$
\begin{aligned}
& \Delta G^{o}=-R T \ln K_{c} \\
& \Delta G^{o}=\Delta G^{o}+T \Delta S^{o} \\
& \log K_{c}=\frac{\Delta S^{o}}{2.303 R}-\frac{\Delta H^{o}}{2.303 R T} \quad \text { (Van't Hoff equation) }
\end{aligned}
$$

$\left(\Delta \mathrm{S}^{\circ}\right)$ and $\left(\Delta \mathrm{H}^{\circ}\right)$ values were found from the y-intercept $\left(\Delta \mathrm{S}^{\circ} / 2.303 \mathrm{R}\right)$ and the slope of the curve $\left(\Delta \mathrm{H}^{\circ} / 2.303 \mathrm{R}\right)$, respectively. Thermodynamic analysis (Table 1) indicated that adsorption with $\mathrm{BC}$ composite capsules for the removal of $\mathrm{Cr}(\mathrm{VI})$ ions was endothermic in nature. At the same time, the adsorption energy of this process was found as $8-16 \mathrm{~kJ} \mathrm{~mol}^{-1}$ in D-R isotherm for the adsorption of $\mathrm{Cr}(\mathrm{VI})$ by BC.

The positive value of enthalpy and the results of D-R isotherm indicated that mechanisms such as ion exchange, electrostatic interaction and complexation were dominant for $\mathrm{Cr}(\mathrm{VI})$ adsorption with $\mathrm{BC}$. Moreover, the negative value of Gibb's free energy for $\mathrm{Cr}(\mathrm{VI})$ adsorption by $\mathrm{BC}$ indicated that $\mathrm{Cr}(\mathrm{VI})$ removal process was spontaneous. $\Delta \mathrm{S}^{\circ}$ value for $\mathrm{Cr}(\mathrm{VI})$ adsorption was also found positive. Positive $\Delta \mathrm{S}^{\circ}$ value referred to an increase in entropy in the solid-liquid interface throughout the adsorption process. According to these thermodynamic results, it was resulted that adsorption of $\mathrm{Cr}(\mathrm{VI})$ ions by $\mathrm{BC}$ composite capsules was a spontaneous reaction. Similar results were obtained in some studies in the literature [30, 44-47]. 


\subsection{Desorption studies}

Desorption studies are important to economic point of view and to assess the reusability of $\mathrm{BC}$ composite capsules as a promising adsorbent for waste water treatment. To remove the adsorbed $\mathrm{Cr}$ (VI) ions on the $\mathrm{BC}$ surface, $0.1 \mathrm{M} \mathrm{NaOH}$ solution was used. After the adsorption equilibrium study, $20 \mathrm{~mL}$ of $0.1 \mathrm{M} \mathrm{NaOH}$ solution was added to $1 \mathrm{~g} \mathrm{Cr}(\mathrm{VI})$ adsorbed $\mathrm{BC}$ and the mixture was stirred continuously at room temperature for 60 minutes. Then the adsorbent was treated with $1 \mathrm{M} \mathrm{HCl}$. To remove $\mathrm{NaOH}$ ond $\mathrm{HCl}$ contamination on the surface of the adsorbent, regenerated $\mathrm{BC}$ was washed several times with MilliQ water. Then, the regenerated $\mathrm{BC}$ was reused at $\mathrm{pH} 2.1$ for 5 adsorption cycles. Therefore, it has been concluded that the $\mathrm{BC}$ composite adsorbent has excellent recycle ability to remove $\mathrm{Cr}(\mathrm{VI})$ from the aqueous solution. The results are shown in Figure 5.

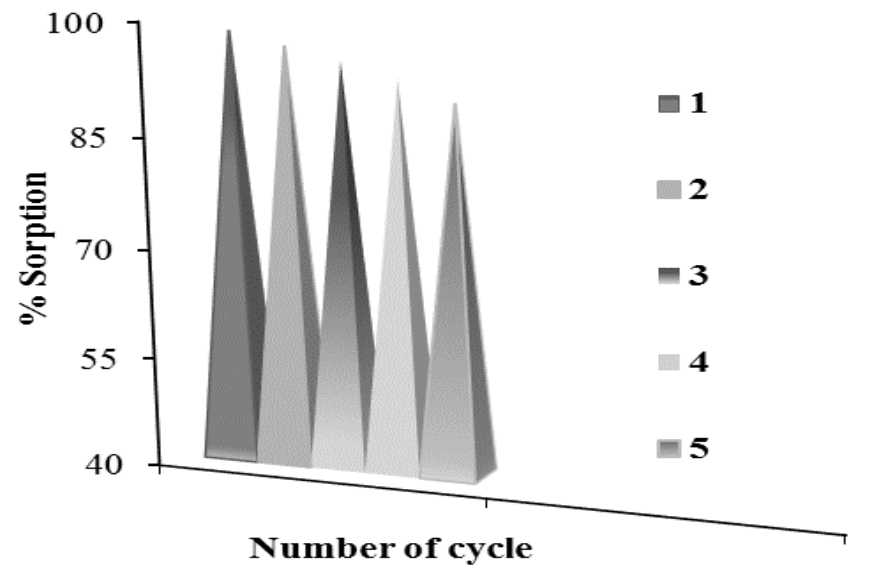

Figure 5. Adsorption-desorption cycles for $\mathrm{Cr}(\mathrm{VI})$ with $\mathrm{BC}$ composite adsorbent.

\section{CONCLUSIONS}

As a result of this study, effcient results were calculated for the removal of $\mathrm{Cr}(\mathrm{VI})$ by BC composite. When compared to other adsorbents obtained from natural materials in the literature, the usage of this composite capsule has a potential for large-scale adsorption processes under the required optimization conditions. As a conclusion, maximum removal was obtained at $\mathrm{pH}$ 2. Optimum adsorbent dosage was determined as $0.04 \mathrm{~g}$ for $\mathrm{Cr}(\mathrm{VI})$ adsorption on $\mathrm{BC}$. At the same time, as the initial concentration was increased, the removal rate of $\mathrm{Cr}(\mathrm{VI})$ decreased. The obtained results of isotherm models indicated that the experimental data were well fitted to Scatchard adsorption isotherm and the adsorption capacity was calculated from this isotherm model. While the maximum adsorption capacity of the raw bentonite clay for removal $\mathrm{Cr}$ (VI) was calculated as $11.076 \mathrm{mg} / \mathrm{g}$, the adsorption capacity of chitosan-coated Bentonite clay composite capsules (BC) for the removal of $\mathrm{Cr}(\mathrm{VI})$ was found as 106.444 $\mathrm{mg} / \mathrm{g}$ which is a quite high value. According to thermodynamic results, while positive $\Delta \mathrm{H}^{\circ}$ value indicated that adsorption was endothermic, positive $\Delta \mathrm{S}^{\circ}$ value indicated that entropy increased in adsorption process and the reaction was induced. Negative values of standard free energy showed that the process was spontaneous. Both thermodynamic results and the adsorption energy value found by $\mathrm{D}-\mathrm{R}$ isotherm $(E=8.06 \mathrm{kj} / \mathrm{mol})$ resulted that mechanisms such as ion exchange, electrostatic interaction and complexation were dominant for $\mathrm{Cr}(\mathrm{VI})$ adsorption on BC. These findings proved that obtaining different composites by using different clays and chitosan might result in materials which have different chemical composition and different surface morphology which are more effective. As a conclusion, heavy metal as well as dyes and other pollutants can be removed by these composite materials in higher removal efficiencies.

\section{CONFLICT OF INTEREST}

The author declares no conflict of interest.

\section{ACKNOWLEDGMENT}

I would like to thank Associate Professor Serpil Edebali for her support in preparing this study.

\section{REFERENCES}

1. Mudzielwana, R., Gitari, M. W., Akinyemi, S. A., \& Msagati, T. A. M. Performance of Mn 2+-modified bentonite clay for the removal of fluoride from aqueous solution. South African Journal of Chemistry, 71(1), 15. (2018)

2. Edebali, S. Alternative Composite Nanosorbents Based on Turkish Perlite for the Removal of $\mathrm{Cr}(\mathrm{VI})$ from Aqueous Solution. Journal of Nanomaterials, 2015. (2015)

3. Auta, M., \& Hameed, B. H. Chitosan-clay composite as highly effective and low-cost adsorbent for batch and fixed-bed adsorption of methylene blue. Chemical Engineering Journal, 237, 352. (2014)

4. Fida, H., Guo, S., \& Zhang, G. Preparation and characterization of bifunctional Ti-Fe kaolinite composite for $\mathrm{Cr}(\mathrm{VI})$ removal. Journal of Colloid and Interface Science. (2015)

5. Uddin, M. K. A review on the adsorption of heavy metals by clay minerals, with special focus on the past decade. Chemical Engineering Journal. (2017)

6. Ghomri, F., Lahsini, A., Laajeb, A., \& Addaou, A. The removal of heavy metal ions (copper, zinc, nickel and cobalt) by natural bentonite. LARHYSS Journal ISSN 1112-3680, (12). (2013)

7. Niazi, L., Lashanizadegan, A., \& Sharififard, H. Chestnut oak shells activated carbon: Preparation, characterization and application for $\mathrm{Cr}$ (VI) removal from dilute aqueous solutions. Journal of Cleaner Production. (2018)

8. Gupta, V. K., Chandra, R., Tyagi, I., \& Verma, M. Removal of hexavalent chromium ions using $\mathrm{CuO}$ nanoparticles for water purification applications. Journal of Colloid and Interface Science. (2016)

9. Yang, J., Yu, M., \& Chen, W. Adsorption of hexavalent chromium from aqueous solution by activated carbon prepared from longan seed: Kinetics, equilibrium and thermodynamics. Journal of Industrial and Engineering Chemistry. (2015)

10. Ghaneian, M. T., Bhatnagar, A., Ehrampoush, M. H., Amrollahi, M., Jamshidi, B., Dehvari, M., \& Taghavi, M. Biosorption of hexavalent chromium from aqueous solution onto pomegranate seeds: kinetic modeling studies. International Journal of Environmental Science and Technology. (2017)

11. Qi, W., Zhao, Y., Zheng, X., Ji, M., \& Zhang, Z. Adsorption behavior and mechanism of $\mathrm{Cr}(\mathrm{VI})$ using Sakura waste from aqueous solution. Applied Surface Science. (2016)

12. Nasseh, N., Taghavi, L., Barikbin, B., \& Khodadadi, M. Advantage of almond green hull over its resultant ash for chromium(VI) removal from aqueous solutions. International Journal of Environmental Science and Technology. (2017)

13. Khalfa, L., Cervera, M. L., Bagane, M., \& Souissi-Najar, S. Modeling of equilibrium isotherms and kinetic studies of $\mathrm{Cr}$ (VI) adsorption into natural and acid-activated clays. Arabian Journal of Geosciences, 9(1), 75. (2016)

14. Rathnayake, S. I., Martens, W. N., Xi, Y., Frost, R. L., \& Ayoko, G. A. Remediation of Cr (VI) by inorganic-organic clay. Journal of Colloid and Interface Science. (2017)

15. Qiu, W., Yang, D., Xu, J., Hong, B., Jin, H., Jin, D., Wang, X. Efficient removal of $\mathrm{Cr}$ (VI) by magnetically separable CoFe2O4/activated carbon composite. Journal of Alloys and Compounds, 678, 179. (2016)

16. Vunain, E., Mishra, A. K., \& Mamba, B. B. Dendrimers, mesoporous silicas and chitosan-based nanosorbents for the removal of heavy-metal ions: A review. International Journal of Biological Macromolecules. (2016)

17. Alhaji, N. M. I., \& Begum, K. M. T. M. Optimization and Kinetic Study for the Removal of Chromium (VI) Ions by Acid Treated Sawdust Chitosan Composite Beads. International Research Journal of Pure and Applied Chemistry, 5(2), 160. (2015)

18. Moussout, H., Ahlafi, H., Aazza, M., \& El Akili, C. Performances of local chitosan and its nanocomposite 5\%Bentonite/Chitosan in the removal of chromium ions $(\mathrm{Cr}(\mathrm{VI}))$ from wastewater. International Journal of Biological Macromolecules, 108, 1063. (2018)

19. Liu, Q., Yang, B., Zhang, L., \& Huang, R. Adsorptive removal of Cr(VI) from aqueous solutions by cross-linked chitosan/bentonite composite. Korean Journal of Chemical Engineering, 32(7), 1314. (2015)

20. Chen, L., Wu, P., Chen, M., Lai, X., Ahmed, Z., Zhu, N., ... Liu, T. Preparation and characterization of the eco-friendly chitosan/vermiculite biocomposite with excellent removal capacity for cadmium and lead. Applied Clay Science. (2018)

21. Biswas, S., Islam, M. M., Hasan, M. M., Rimu, S. H., Khan, M. N., Haque, P., \& Rahman, M. M. Evaluation of Cr (VI) Ion Removal from Aqueous Solution by Bio-Inspired Chitosan-Clay Composite: Kinetics and Isotherms. Iranian Journal of Chemical Engineering, 15(4). (2018)

22. Yadav, V. B., Gadi, R., \& Kalra, S. Clay based nanocomposites for removal of heavy metals from water: A review. Journal of environmental management, 232, 803. (2019) 
23. Sargin, I., Kaya, M., Arslan, G., Baran, T., \& Ceter, T. Preparation and characterisation of biodegradable pollen-chitosan microcapsules and its application in heavy metal removal. Bioresource Technology, 177, 1. (2015)

24. Moussout, H., Ahlafi, H., Aazza, M., \& Amechrouq, A. Bentonite/chitosan nanocomposite: preparation, characterization and kinetic study of its thermal degradation. Thermochimica Acta, 659, 191. (2018)

25. Giannakas, A., \& Pissanou, M. Chitosan/Bentonite Nanocomposites for Wastewater Treatment: A Review. SF J Nanochem Nanotechnol. 2018; 1 (1), 1010. (2018)

26. Futalan, C. M., Kan, C. C., Dalida, M. L., Hsien, K. J., Pascua, C., \& Wan, M. W. Comparative and competitive adsorption of copper, lead, and nickel using chitosan immobilized on bentonite. Carbohydrate Polymers. (2011)

27. Waheed Thany, Z., \& Mousa Ridha, A. Use of chitosan impregnated modified bentonite as an adsorbent for remediation of oil spill from aqueous solution. International Journal of Engineering \&amp; Technology, 7(4), 4380. (2018)

28. Zou, C., Jiang, W., Liang, J., Sun, X., \& Guan, Y. Removal of Pb (II) from aqueous solutions by adsorption on magnetic bentonite. Environmental Science and Pollution Research, 26(2), 1315. (2019)

29. Ugwu, I. M., \& Igbokwe, O. A. Sorption of Heavy Metals on Clay Minerals and Oxides: A Review. In Advanced Sorption Process Applications. IntechOpen. (2019)

30. Altun, T., Parlayıc1, Ş., \& Pehlivan, E. Hexavalent chromium removal using agricultural waste "rye husk". Desalination and Water Treatment. (2016)

31. Melo, J. S., \& D'Souza, S. F. Removal of chromium by mucilaginous seeds of Ocimum basilicum. Bioresource Technology. (2004)

32. Matouq, M., Jildeh, N., Qtaishat, M., Hindiyeh, M., \& Al Syouf, M. Q. The adsorption kinetics and modeling for heavy metals removal from wastewater by Moringa pods. Journal of Environmental Chemical Engineering. (2015)

33. Li, J., Cai, J., Zhong, L., Cheng, H., Wang, H., \& Ma, Q. Adsorption of reactive red 136 onto chitosan/montmorillonite intercalated composite from aqueous solution. Applied Clay Science, 167, 9. (2019)

34. Zhao, Y., Qi, W., Chen, G., Ji, M., \& Zhang, Z. Behavior of Cr(VI) removal from wastewater by adsorption onto $\mathrm{HCl}$ activated Akadama clay. Journal of the Taiwan Institute of Chemical Engineers. (2015)

35. Akram, M., Bhatti, H. N., Iqbal, M., Noreen, S., \& Sadaf, S. Biocomposite efficiency for $\mathrm{Cr}(\mathrm{VI})$ adsorption: Kinetic, equilibrium and thermodynamics studies. Journal of Environmental Chemical Engineering. (2017)
36. Mishra, A., Dubey, A., \& Shinghal, S. Biosorption of chromium(VI) from aqueous solutions using waste plant biomass. International Journal of Environmental Science and Technology. (2015)

37. Georgieva, V. G., Tavlieva, M. P., Genieva, S. D., \& Vlaev, L. T. Adsorption kinetics of $\mathrm{Cr}(\mathrm{VI})$ ions from aqueous solutions onto black rice husk ash. Journal of Molecular Liquids. (2015)

38. Pandey, S., \& Mishra, S. B. Organic-inorganic hybrid of chitosan/organoclay bionanocomposites for hexavalent chromium uptake. Journal of Colloid and Interface Science, 361(2), 509. (2011)

39. Fouodjouo, M., Fotouo-Nkaffo, H., Laminsi, S., Cassini, F. A., de BritoBenetoli, L. O., \& Debacher, N. A. Adsorption of copper (II) onto cameroonian clay modified by non-thermal plasma: Characterization, chemical equilibrium and thermodynamic studies. Applied Clay Science. (2017)

40. Lin, J., Wu, Y., Khayambashi, A., Wang, X., \& Wei, Y. Preparation of a novel $\mathrm{CeO} 2 / \mathrm{SiO} 2$ adsorbent and its adsorption behavior for fluoride ion. Adsorption Science and Technology, 36(1-2), 743. (2018)

41. Ayawei, N., Ebelegi, A. N., \& Wankasi, D. Modelling and Interpretation of Adsorption Isotherms. Journal of Chemistry. (2017)

42. Parlayici, S. Alginate-coated perlite beads for the efficient removal of methylene blue, malachite green, and methyl violet from aqueous solutions: kinetic, thermodynamic, and equilibrium studies. Journal of Analytical Science and Technology, 10(1), 4. (2019)

43. Chaudhry, S. A., Khan, T. A., \& Ali, I. Equilibrium, kinetic and thermodynamic studies of $\mathrm{Cr}(\mathrm{VI})$ adsorption from aqueous solution onto manganese oxide coated sand grain (MOCSG). Journal of Molecular Liquids. (2017)

44. Liu, X., \& Lee, D. Thermodynamic parameters for adsorption equilibrium of heavy metals and dyes from wastewaters. Bioresource Technology, 160, 24. (2014)

45. Salih, S. S., \& Ghosh, T. K. Highly efficient competitive removal of $\mathrm{Pb}$ (II) and $\mathrm{Ni}$ (II) by chitosan/diatomaceous earth composite. Journal of environmental chemical engineering, 6(1), 435. (2018)

46. Tulun, S., Bahadir, T., Simsek, I., \& Karatas, M. THE REMOVAL OF NICKEL IONS WITH WALNUT SHELL. Turkish Journal of Engineering (TUJE), 3(2), 102. (2019)

47. Konicki, W., \& Pełech, I. Removing Cationic Dye from Aqueous Solutions Using as-grown and Modified Multi-Walled Carbon Nanotubes. Polish Journal of Environmental Studies, 28(2), 717. (2018) 